\title{
Thyroid Dysfunction in Metabolic Syndrome Patients in a Tertiary Care Hospital
}

\author{
Chakradhar M. ${ }^{1}$, Chakravarthy D. J.K. ${ }^{2}$, Bhaskar Dorapudi S.C.H. ${ }^{3}$, Kiran Deedi M. ${ }^{4}$, Bhavani Prasad N. ${ }^{5}$ \\ ${ }^{1}$ Department of General Medicine, GSL Medical College and General Hospital, Rajahmundry, Andhra \\ Pradesh, India. ${ }^{2}$ Department of General Medicine, GSL Medical College and General Hospital, \\ Rajahmundry, Andhra Pradesh, India. ${ }^{3}$ Department of General Medicine, GSL Medical College and \\ General Hospital, Rajahmundry, Andhra Pradesh, India. ${ }^{4}$ Central Research Laboratory, GSL Medical \\ College and General Hospital, Rajahmundry, Andhra Pradesh, India. ${ }^{5}$ Department of General \\ Medicine, GSL Medical College and General Hospital, Rajahmundry, Andhra Pradesh, India.
}

\section{ABSTRACT}

\section{BACKGROUND}

Metabolic syndrome is a prevalent non-communicable disease in the present era. It manifests as obesity, impaired fasting blood glucose, dyslipidaemia, and hypertension. Hypothyroidism causes hypertension, dyslipidaemia, and impaired carbohydrates metabolism, which are all components of metabolic syndrome. The cardiovascular system is very sensitive to thyroid hormones.

\section{METHODS}

A cross sectional study was conducted from October 2017 to March 2019 in adult population aged 18 years and above, with features of Metabolic syndrome diagnosed according to National Cholesterol Education Programme Adult Treatment Panel - III (NCEP ATP III) criteria. Study was conducted in the department of general medicine, GSL Medical College and General hospital, Rajahmundry, Andhra Pradesh.

\section{RESULTS}

In a total of 134 patients with metabolic syndrome, 39 were male $(29.2 \%)$ and 95 were female $(70.8 \%)$. The mean age of the study population was $54.63 \pm 10.9$ years. The prevalence of thyroid dysfunction in the present study is $28.4 \%$. In the present study, metabolic syndrome is found to be significantly $(p=0.032)$ associated with thyroid dysfunction.

\section{CONCLUSIONS}

Both hypothyroidism and hyperthyroidism are associated with cardiovascular manifestations. Hypothyroidism and subclinical hypothyroidism cause cardiovascular manifestations along with metabolic changes. Investigating the thyroid function status may be considered as a part of screening in patients with metabolic syndrome.

\section{KEY WORDS}

Metabolic Syndrome, Hypothyroidism, Waist Circumference, Dyslipidaemia
Corresponding Author: Chakravarthy D. J. K., Assistant Professor, Department of General Medicine, GSL Medical College and General Hospital, Rajahmundry-533296, Andhra Pradesh, India.

E-mail:drdjkc@gmail.com

DOI: $10.14260 / \mathrm{jemds} / 2020 / 459$

How to Cite This Article:

Chakradhar M, Chakravarthy DJK, Dorapudi BSCH, et al. Thyroid dysfunction in metabolic syndrome patients in a tertiary care hospital. J. Evolution Med. Dent. Sci. 2020;9(30):2103-2108, DOI: $10.14260 / \mathrm{jemds} / 2020 / 459$

Submission 01-02-2020,

Peer Review 18-06-2020,

Acceptance 25-06-2020,

Published 27-07-2020.

Copyright (c) 2020 JEMDS. This is an open access article distributed under Creative Commons Attribution License [Attribution 4.0 International (CC BY 4.0)] 


\section{BACKGROUND}

According to available studies, $25-35 \%$ of the adult population in India is affected by metabolic syndrome. ${ }^{[1]}$ According to the National Cholesterol Education Programme Adult Treatment Panel-III guidelines, metabolic syndrome is diagnosed when a patient has at least 3 of the following five conditions. ${ }^{[2]}$

- Fasting glucose $\geq 110 \mathrm{mg} / \mathrm{dL}$ (or receiving drug therapy for hyperglycaemia)

- $\quad$ Blood pressure $\geq 130 / 85 \mathrm{~mm} \mathrm{Hg}$ (or receiving drug therapy for hypertension)

- Triglycerides $\geq 150 \mathrm{mg} / \mathrm{dL}$ (or receiving drug therapy for hypertriglyceridemia)

- HDL-Cholesterol $<40 \mathrm{mg} / \mathrm{dL}$ in men or $<50 \mathrm{mg} / \mathrm{dL}$ in women (or receiving drug therapy for reduced HDL-C)

- Waist circumference $\geq 90 \mathrm{~cm}$ in men or $\geq 80 \mathrm{~cm}$ in women.

Increased mechanisation, decreased physical activity, consumption of fat-rich, fast and junk food has resulted in an increased prevalence of obesity and insulin resistance giving rise to metabolic syndrome. Non-communicable disease (NCD) prevalence rates are very high in subjects with metabolic syndrome. ${ }^{[3,4]}$ Early identification of factors predictive of metabolic syndromes like hypertension and obesity and remedial measures will help in the prevention of NCD like diabetes and cardiovascular disease.

Metabolic syndrome and thyroid dysfunction association was demonstrated in many recent studies. Thyroid dysfunction is altered states of thyroid-stimulating hormone level with or without alteration in Tri iodothyronine (T3), Tetra iodothyronine (T4). People with high Thyroidstimulating hormone (TSH) levels were found to have a twofold rise in the prevalence of metabolic syndrome.[5] Subclinical hypothyroidism with increased TSH level was also seen to be associated with increased risk of coronary heart disease. Both atherosclerosis and dyslipidaemia are common in hypothyroidism. ${ }^{[6]}$ As both metabolic syndrome and thyroid dysfunction are individual and independent risk factors for the development of atherosclerotic Cardiovascular Disease (CVD), concurrent existence of both in the same individual will further increase cardiovascular risk in the individual.

Deficiency of thyroid hormones can cause cardiovascular disease and may aggravate any pre-existing conditions. Thyroid hormone imbalances causing thyroid dysfunction, having its effect on lipid metabolism and blood pressure forms a risk factor for atherosclerotic cardiovascular disease.[7] Thyroid-stimulating hormone exerts an independent effect on lipid metabolism by inducing adipogenesis, lipolysis, and this activity is mediated by increased activity of HMG CoA. Thyroid hormones exert impact on HDL, LDL, cholesterol whereas thyroid-stimulating hormone on Triglycerides. ${ }^{[8]}$

On the one hand, obesity causes alterations in thyroid hormones and on the other hand, subclinical hypothyroidism results in slow metabolism leading to obesity. So, it is not known whether the change in thyroid hormone level a cause or an effect of obesity (metabolic syndrome).

Objective of the study was to assess the thyroid status of the individuals with metabolic syndrome and to examine the impact of thyroid dysfunction on cardiovascular risk in metabolic syndrome subjects.

\section{METHODS}

This cross-sectional study was conducted in department of general medicine, GSL Medical College and General Hospital, Rajahmundry, Andhra Pradesh. The study was approved by ethics committee and informed consent was obtained. All 134 patients with metabolic syndrome, satisfying inclusion and exclusion criteria attended as outpatients and inpatients to the department of General medicine over a period of 18 months (Oct. 2017 - Mar. 2019) were included in the study. The sample study was taken based on the convenience of the study. 134 subjects aged 18 years and above with features of Metabolic syndrome according to NCEP ATP III criteria (at least 3 out of 5 criteria) (modified for south east population by WHO, Diabetes and heart in India, ICP guidelines) ${ }^{[2]}$ were included in the study group. Patients with primary thyroid disorder, who have had irradiation of thyroid gland, who have undergone thyroidectomy/ thyroid surgeries, on Anti-thyroid drugs were excluded from the study.

Patients suffering with liver disease, renal abnormalities, congestive heart failure and pregnant women are excluded. Patients using the drugs that alter thyroid functions and lipid levels such as Statins, Lithium, Amiodarone, Oral contraceptive pills were also excluded.

Detailed medication history, weight, height, BMI, and waist circumference were recorded in a proforma. Blood pressure was recorded in right upper limb. After a noted eight hours of fasting, venous blood sample was drawn for measuring thyroid profile, lipid profile and FBS.

Enzymatic colorimetric method with Semi auto analyser was used for measuring fasting blood sugar values. Triglyceride levels were determined in the serum by commercially available kits on an Erba Mannheim -360 analyser. High-density lipoprotein was measured by using the direct high-density lipoprotein method. The thyroid hormone assay (TSH, T3 and T4) were done by Chemiluminescence Immuno Assay (CLIA) using ADVIA Centaur equipment.

\section{Statistical Analysis}

Data entry and statistical analysis were performed with the help of Microsoft excel 2007 and SPSS version 21.0. Categorical variables were presented as numbers and percentages. All descriptive data was expressed as Mean \pm standard deviation and percentages. Chi-square test was used to assess the association among different categorical variables. Spearman's correlation was performed to find out the relation between different continuous variables. For all statistical analyses $\mathrm{p}<0.05$ was considered statistically significant.

\section{RESULTS}

Of the 134 patients with metabolic syndrome 39 were male $(29.2 \%)$ and 95 were female $(70.8 \%)$. The mean age of the study population was $54.63 \pm 10.9$ years with a range from 31 to 87 years (Table 1 ). 


\begin{tabular}{|cccc|}
\hline Age (Years) & Male & Female & Total Number \\
$30-39$ & 2 & 5 & $7(5 \%)$ \\
$40-49$ & 16 & 27 & $43(32 \%)$ \\
$50-59$ & 12 & 25 & $37(27 \%)$ \\
$60-69$ & 7 & 28 & $35(26 \%)$ \\
$70-79$ & 2 & 8 & $10(7 \%)$ \\
$80-89$ & 0 & 2 & $2(1 \%)$ \\
\hline \multicolumn{4}{r|}{ Table 1. Age and Gender Distribution of Subjects } \\
with Metabolic Syndrome \\
\hline
\end{tabular}

Out of 134 patients, 44 patients fulfilled three out of five metabolic syndrome parameters, 64 patients fulfilled 4 out of 5 metabolic parameters and 26 patients fulfilled all the five metabolic syndrome parameters. Patients were divided into four groups, based on T3, T4 and TSH values, and statistical analysis was done. Ninety-six patients are euthyroid, 11 patients had hypothyroidism, 21 had subclinical hypothyroidism, and six patients had hyperthyroidism. In the present study, there are no cases of subclinical hyperthyroidism (Table 2).

\begin{tabular}{|cccc|}
\hline Group & Male & Female & Total \\
Euthyroid & 31 & 65 & $96(71.6 \%)$ \\
Hypothyroid & 3 & 8 & $11(8.2 \%)$ \\
Subclinical hypothyroidism & 3 & 18 & $21(15.7 \%)$ \\
Hyperthyroidism & 2 & 4 & $6(4.5 \%)$ \\
\hline Table 2. Gender Wise Distribution of Subjects \\
\\
with Thyroid Dysfunction & \\
\hline
\end{tabular}

Mean T4 levels of the study participants was $78.7 \pm 28$ with a range of 5 to $154 \mathrm{mcg} / \mathrm{dL}$. Mean TSH levels of the study participants were $4.7 \pm 7$ with a range of 0.01 to $60 \mathrm{IU} / \mathrm{dL}$.

The prevalence of dysfunctional thyroid in present study is 28.4\%. Among thyroid dysfunction cases, subclinical hypothyroidism has shown a high prevalence of $15.7 \%$. Hypothyroidism and Hyperthyroidism had a prevalence of $8.2 \%$ and $4.5 \%$ respectively. Prevalence of thyroid dysfunction in females with metabolic syndrome is $70.9 \%$, and males with metabolic syndrome are $29.1 \%$.

In the age group of 30-39 years, among seven subjects, two patients had hypothyroidism, one patient had subclinical hypothyroidism, and 1 had hyperthyroidism. In the age group of 40-49 years, among 43 subjects, 3 patients had hypothyroidism, 7 had subclinical hypothyroidism, and 3 had hyperthyroidism. In the group of 50-59, among 37 subjects, 3 had hypothyroidism, 7 had subclinical hypothyroidism, and in the group above 60 years, 3 had hypothyroidism, 8 had subclinical hypothyroidism and 2 had hyperthyroidism.

Twenty-six subjects fulfilled five criteria of metabolic syndrome, 2 had thyroid dysfunction. Sixty-four subjects fulfilled four criteria of metabolic syndrome, 24 had thyroid dysfunction. Forty-four subjects fulfilled three criteria of metabolic syndrome, 12 had thyroid dysfunction (Table 3).

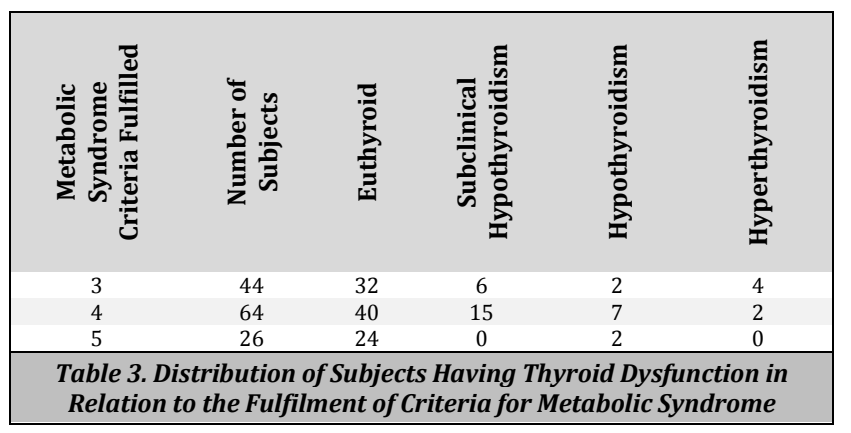

In the present study metabolic syndrome is found significantly $(p=0.032)$ associated with thyroid dysfunction. The likelihood ratio of thyroid dysfunction in metabolic syndrome is found to be 0.006 . In the present study, 30 out of 95 female subjects having metabolic syndrome are found to have thyroid dysfunction. Sixty-five subjects (68.4\%) are Euthyroid, 18 (18.9\%) are having subclinical hypothyroidism, $8(8.4 \%)$ are having hypothyroidism, $4(4.2 \%)$ are having hyperthyroidism. No subclinical hyperthyroidism is found in female subjects. Eight subjects out of 39 males having metabolic syndrome are found with thyroid dysfunction. 31 (79.5\%) are Euthyroid, 3 (7.7\%) are having subclinical hypothyroidism, $3(7.7 \%)$ are having hypothyroidism, 2 (5.1\%) are having hyperthyroidism. No significant association was found between male and female subjects of metabolic syndrome suffering from thyroid dysfunction (Table 4).

\begin{tabular}{|cccc|}
\hline Thyroid Status & Male (n=95) & Female (n=39) & P Value \\
Euthyroid & $65(68.5 \%)$ & $31(79.5 \%)$ & \\
Subclinical Hypothyroid & $18(18.9 \%)$ & $3(7.7 \%)$ & \\
Hypothyroid & $8(8.4 \%)$ & $3(7.7 \%)$ & 0.427 \\
Hyperthyroid & $4(4.2 \%)$ & $2(5.1 \%)$ & \\
\hline \multicolumn{3}{|c|}{ Table 4. Sex Distribution of Subjects Having } \\
Thyroid Dysfunction with Metabolic Syndrome & \\
\hline \multicolumn{2}{|c|}{ Data was expressed in number (n) and percentage (\%); } \\
p value was calculated by using Chi-Square test.
\end{tabular}

Each of the components of metabolic syndrome was studied and the relation of these individual components with thyroid dysfunction was detailed (Table 5).

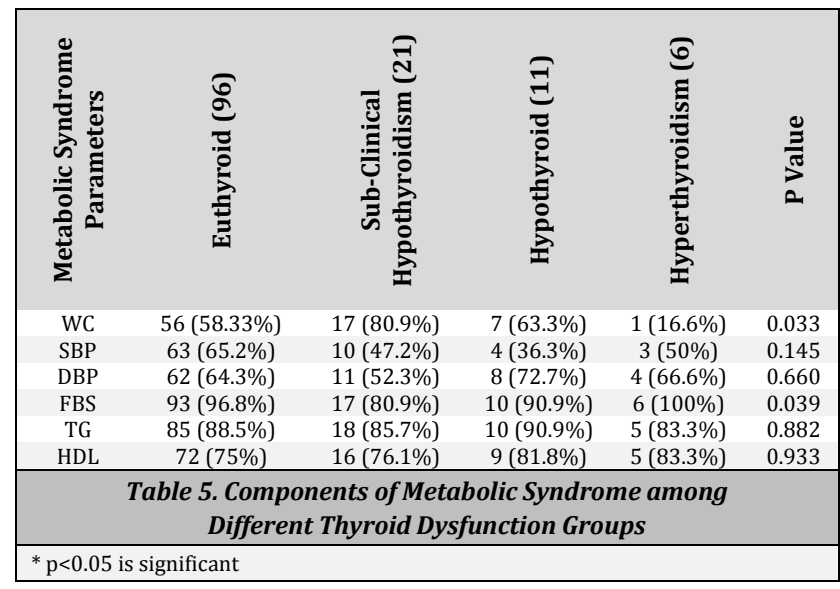

Out of all individual components of the metabolic syndrome, fasting blood sugar and waist circumference above reference range was found to be statistically significant with thyroid dysfunction (p 0.033 and 0.039 respectively).

\begin{tabular}{|c|c|c|c|c|}
\hline \multirow{2}{*}{$\begin{array}{c}\text { Metabolic } \\
\text { Syndrome } \\
\text { Parameters }\end{array}$} & \multicolumn{2}{|c|}{ TSH } & \multicolumn{2}{|c|}{ T4 } \\
\hline & $\mathbf{r}$ & $\mathbf{p}$ & $\mathbf{r}$ & $\mathbf{p}$ \\
\hline $\begin{array}{l}\text { Waist } \\
\text { circumference }\end{array}$ & 0.190 & 0.038 & -0.178 & 0.04 \\
\hline $\begin{array}{l}\text { Systolic blood } \\
\text { pressure }\end{array}$ & -0.104 & 0.230 & 0.75 & 0.387 \\
\hline $\begin{array}{l}\text { Diastolic blood } \\
\text { pressure }\end{array}$ & 0.074 & 0.392 & -0.65 & 0.45 \\
\hline $\begin{array}{l}\text { Fasting blood } \\
\text { sugar }\end{array}$ & -0.79 & 0.364 & 0.151 & 0.08 \\
\hline Triglycerides & 0.12 & 0.88 & 0.2 & 0.98 \\
\hline HDL Cholesterol & -0.03 & 0.975 & 0.129 & 0.138 \\
\hline \multicolumn{5}{|c|}{$\begin{array}{c}\text { Table 6. Correlation of Components of Metabolic Syndrome } \\
\text { with T4 and TSH }\end{array}$} \\
\hline
\end{tabular}


Among all the components of metabolic syndrome, waist circumference showed a significant positive correlation with TSH and a significant negative correlation with T4 (Table 6).

\section{DISCUSSION}

Metabolic syndrome is a constellation of abnormalities, including increase in weight (obese), having hypertension, abnormal lipid profile with elevated triglycerides and low values of high-density lipoproteins, increased values of fasting blood sugars. Patients of metabolic syndrome had a higher risk of developing diabetes and cardiovascular diseases in future. Thyroid dysfunction is common among patients of metabolic syndrome. In the present study, the prevalence of thyroid dysfunction in metabolic syndrome patients is $28.4 \%$. In various studies conducted in India, Nepal, Middle East and African countries the prevalence of thyroid dysfunction in metabolic syndrome patients is in the range of $21-51 \% .^{[9-12]}$ Subclinical hypothyroidism has associated with atherosclerotic cardiovascular disease due to change in coagulation parameters, hyper-homocystinaemia and inflammation process.[13-16] Hyperthyroidism is the most common condition found in the general population, female population and metabolic syndrome patients. The prevalence of subclinical hypothyroidism in various studies conducted in India by Saluja et al.,[17] (37\%), Shantha et al.,[18] (21.9\%), Khatiwada et al.,[19] (26.6\%), Kota et al.,[20] (22\%), Gyawadi et al.,[12] (29.22\%) are as described. Similar observations were made in the present study, as the prevalence of subclinical hypothyroidism is $15.7 \%$.

In Kventy et al.,[21] and Rotterdam study[22] reported, prevalence of subclinical hypothyroidism in the general population was $19.7 \%$ and $10.8 \%$ respectively. In Frementle ${ }^{[23]}$ diabetes study and Uzunlulu et al.,[10] prevalence is found to be $8.6 \%$ and $5.8 \%$ respectively. The present study suggests that female with metabolic syndrome has the highest risk for subclinical hypothyroidism along with cardiovascular manifestation, which correlates with other studies like Uzunlulu et al.,[10] (16.5\%) and Kota et al.,[20] (22\%). But it is not statistically significant in the present study.

In the present study, the mean age of the population with thyroid dysfunction is $54.63 \pm 10.93$ years, and this study was compared to other studies like Vaishali et al.,[11] where the mean age is $47.9 \pm 10.96$ years, in Ogbera et al.,[24] study the mean age is $44.5 \pm 14$ years. Data shows that increasing age represents a significant risk factor for thyroid dysfunction in metabolic syndrome patients which was similar to the present study, and it is correlated with Shantha et al.,[18]

In the present study group prevalence of thyroid dysfunction in a female with metabolic syndrome was $70.1 \%$ and men with metabolic syndrome were $28.9 \%$ and this data compared with other study groups like Saluja et al.,[17], which showed a prevalence of $57 \%$ in females and $43 \%$ in males, Vaishali et al.,[11] study showed a prevalence of 75\% in females and $25 \%$ males. Khatiwada et al.,[19] study prevalence is $53 \%$ in females and $47 \%$ in males. In postmenopausal women and elderly women, there is a decrease in sensitivity of $\mathrm{T} 4$ on the pituitary, which would lead to thyroid dysfunction. Autoimmune thyroiditis may be another cause of thyroid dysfunction in postmenopausal women.[25-27]
In the present study, the mean waist circumference of the population with thyroid dysfunction was $85.6 \pm 6.38 \mathrm{~cm}$. This study was compared with other studies like Saluja et al.,[17] study $92.04 \pm 13.21 \mathrm{~cm}$, Deshmukh et al.,[11] study $98.6 \pm 9.7$ $\mathrm{cm}$ and Ogbera et al.,[24] $93.5 \pm 14.1 \mathrm{~cm}$. In the present study, $69.04 \%$ of patients had waist circumference above normal reference range ( $>90 \mathrm{~cm}$ in men and $>80 \mathrm{~cm}$ in women), and obesity was comparatively more in females than men. Arthur et al. showed increased waist circumference in postmenopausal female.[27] Sudhakar et al., showed that waist circumference (>88 cm) is higher in women having dysfunction of thyroid as compared to the other parameters of metabolic syndrome.[28] Patients having increased waist circumference should be screened primarily for metabolic syndrome and later for any thyroid dysfunction.

In the present study, the mean fasting blood glucose of the population with thyroid dysfunction is $154 \pm 46.3 \mathrm{mg} / \mathrm{dL}$. High glycaemic indices may be due to the rising trend of glucose intolerance and diabetes mellitus in the present population because of change in food habits, decreased physical activity and environmental hazards. As a metabolic consequence, increased insulin resistance and hyperinsulinemia are associated with metabolic syndrome. Thyroid dysfunction can be hypothesized that an increase in TSH levels in obese persons with insulin resistance could be due to the association of thyroid receptor resistance to TSH, which is similar to insulin resistance.[29] High levels of TSH in metabolic syndrome patients may be due to hormones secreted by adipose tissue. In this study, hormones like leptin, resistin, adiponectin were not analysed, so can't comment on the effect of these hormones on stimulation of TSH.[29] Thyroid dysfunction requires evaluation on a large scale with the inclusion of various hormones elaborated by adipose tissue. In hyperthyroidism, impaired glucose tolerance may be due to impairment of beta-cell function, which was attributed to elevated levels of thyroid hormones effecting the pancreatic insulin secretion and its peripheral action. ${ }^{[30]}$

In the present study the mean SBP of the population with thyroid dysfunction is $137.57 \pm 19.3 \mathrm{~mm}$ of $\mathrm{Hg}$ and mean diastolic blood pressure of the population with thyroid dysfunction is $88.81 \pm 11.84 \mathrm{~mm}$ of $\mathrm{Hg}$. In hypertension, even though hypothyroidism which is a potentially important cause which was generally overlooked, the pathophysiology mechanisms which are responsible for causing hypertension in thyroid dysfunction patient include circulating catecholamine's, their receptor and renin-angiotensin aldosterone. ${ }^{[30]}$ In patients with mild and subclinical hypothyroidism many important risk factors of cardiovascular system have been identified such as diastolic dysfunction,[31] increased arterial stiffness, ${ }^{[32]}$ endothelial dysfunction,[33] and increase in systemic vascular resistance. [34] Thus a patient with metabolic syndrome and thyroid dysfunction should be screened for cardiovascular dysfunction.

In the present study the mean HDL cholesterol of the population with thyroid dysfunction is $42.76 \pm 6.70 \mathrm{mg} / \mathrm{dL}$ and mean Triglycerides is $180.76 \pm 36.76 \mathrm{mg} / \mathrm{dL}$. In the present study, $88 \%$ of cases had high levels of Triglycerides $<>150$ $\mathrm{mg} / \mathrm{dL})$, and $76 \%$ had low levels of HDL cholesterol $(<50$ in female and $<40$ in male). In the study conducted by Punia et al., ${ }^{[35]}$ reported high Triglycerides in 62\% and low HDL in $83 \%$ of study subjects. Jaya Kumar et al.,[36] reported that $60 \%$ had low HDL, and 55\% had high triglyceride levels. 
Elevation of Triglycerides in thyroid dysfunction like subclinical hypothyroidism and hypothyroidism is due to the reduced removal rate of Triglycerides from plasma, due to decreased activity of hepatic Triglycerides lipases. There is a decrease in the HDL-Cholesterol level in the hyperthyroid patients due to the increased Cholesterol Ester Transfer Protein (CETP) - mediated transfer of cholesteryl esters from HDL to VLDL and increased HDL- mediate catabolism of HDL2.[37,38]

In the present study, the data shows a significant association between the waist circumference with $\mathrm{T} 4(\mathrm{p}=0.04)$ and TSH ( $\mathrm{p}=0.038)$. Gyawali et al.,[12] depicted a significant association between waist circumference and $\mathrm{T} 4(\mathrm{p}=0.002)$ but not with TSH $(\mathrm{p}=0.136)$. This difference in significance may be due to the genetic, environmental factors and intake of iodine, which may vary between different geographical areas of the patients' inhabitancy.

The present study showed an increased prevalence of hypothyroidism and subclinical hypothyroidism in patients of metabolic syndrome, which might have an ill effect on the cardiovascular health. Hypothyroidism causes an increase in lipids levels and hypertension leads to cardiovascular risk. Increased risk of cardiovascular and cerebrovascular events may be seen in patients with metabolic syndrome and dysfunction of thyroid gland. Evaluating the thyroid function in patients of metabolic syndrome may help to identify and prevent the risk of cardiovascular and cerebrovascular events in the patients. A small sample size is a limitation of this study.

\section{CONCLUSIONS}

Thyroid dysfunction is an important entity as a complication in metabolic syndrome patients. From various studies, it is a known fact that the incidence of thyroid hormone abnormality is more in females as compared to males. Of all the various thyroid abnormalities encountered, subclinical hypothyroidism is the most common, followed by hypothyroidism. Cardiovascular risk is observed more in patients who had both thyroid dysfunction and metabolic syndrome together. Thyroid hormones should be assayed in all patients suffering from metabolic syndrome, which may be helpful in early diagnosis of thyroid dysfunction and also useful in reducing the risk of atherosclerotic cardiovascular disease.

Financial or Other Competing Interests: None.

\section{REFERENCES}

[1] Thiruvagounder M, Khan S, Sheriff DS. The prevalence of metabolic syndrome in the local population in India. Biochemia Medica 2010;20(2):249-52.

[2] Parikh RM, Mohan V. Changing definitions of metabolic syndrome. India J Endocrinol Metab 2012;16(1):7-12.

[3] Bhalavi V, Deshmukh PR, Goswami K, et al. Prevalence and correlation of metabolic syndrome in the adolescents of rural Wardha. Indian J Community Med 2015;10(1):43-8.
[4] Tkac I. Metabolic syndrome in relationship to type 2 diabetes an atherosclerosis. Diabetes Res Clin Pract 2005;68 Suppl 1:S2-9.

[5] Oh JY, Sung YA, Lee HJ. Elevated thyroid stimulating hormone levels are associated with metabolic syndrome in euthyroid young women. Korean J Intern Med 2013;28(2):180-6.

[6] Nah EH, Lee JG. The relationship between thyroid function and the risk factors of cardiovascular disease at female medical checkups. Korean J Lab Med 2009;29(4):286-92.

[7] Gyawali P, Takanche JS, Shrestha RK, et al. Pattern of thyroid dysfunction in patients with metabolic syndrome and its relationship with components of metabolic syndrome. Diabetes Metab J 2015;39(1):66-73.

[8] Chin KY, Ima-Nirwana S, Mohamed IN, et al. The relationship of thyroid hormone and thyroid-stimulating hormone with lipid profile in Euthyroid men. Int J Med Sci 2014;11(4):349-55.

[9] Shrestha S, Das BKL, Baral N, et al. Association of metabolic syndrome and its components with thyroid dysfunction in females. Int J Diab Dev Countries 2007;27(1):24-6.

[10] Uzunlulu M, Yorulmaz E, Oguz A. Prevalence of subclinical hypothyroidism in patients with metabolic syndrome. Endocr J 2007;54(1):71-6.

[11] Deshmukh V, Farishta F, Bhole M. Thyroid dysfunction in patients with metabolic syndrome: a cross-sectional, epidemiological, pan-India study. Int J Endocrinol 2018;2018:1-6.

[12] Gyawali P, Takanche JS, Shrestha RK, et al. Pattern of thyroid dysfunction in patients with metabolic syndrome and its relationship with components of metabolic syndrome. Diabetes Metab J 2015;39(1):66-73.

[13] Biondi B, Klein I. Hypothyroidism as a risk factor for cardiovascular disease. Endocrine 2004;24(1):1-13.

[14] Guldiken S, Demir M, Turgut B, et al. Global fibinolytic capacity in patients with subclinical hypothyroidism. Endocr J 2005;52(3):363-7.

[15] Ozmen B, Ozmen D, Parildar Z, et al. Impact of renal function or folate status on aletred plasma homocysteine levels in hypothyroidism. Endocr J 2006;53(1):119-24.

[16] Tuzuc A, Bahceci M, Gokalp D, et al. Subclinical hypothyroidism may be associated with elevated high sensitive C-reactive protein (Low Grade Inflammation) and fasting hyperinsulinemia. Endocr J 2005;52(1):89-94.

[17] Saluja M, Pyarsabadi P, Jelia S, et al. Study of thyroid dysfunction in metabolic syndrome and association with its components. Curr Med Res Pract 2018;8(1):3-7.

[18] Shantha GPS, Kumar AA, Jeyachandran V, et al. Association between primary hypothyroidism and metabolic syndrome and the role of $\mathrm{C}$ reactive protein: $\mathrm{a}$ cross-sectional study from South India. Thyroid Res 2009;2(1):2.

[19] Khatiwada S, Kc R, Sah SK, et al. Thyroid dysfunction and associated risk factors among Nepalese diabetes mellitus patients. Int J Endocrinol 2015;2015:1-5.

[20] Kota SK, Meher LK, Krishna S, et al. Hypothyroidism in metabolic syndrome. Indian J Endocrinol Metab 2012;16(Suppl 2):S332-3.

[21] Kventy J, Heldgaard PE, Bladbjerg EM, et al. Subclinical hypothyroidism is associated with a low grade 
inflammation, increased triglyceride levels and predicts cardiovascular disease in male below 50 years. Clin Endocrinol (Oxf) 2004;61(2):232-8.

[22] Hak AE, Pols HA, Visser TJ, et al. Subclinical hypothyroidism is a independent risk factor for atherosclerosis and myocardial infraction in elderly women: the Rotterdam study. Ann Intern Med 2000;132(4):270-8.

[23] Chubb SAP, Davis WA, Inman Z, et al. Prevalence and progression of subclinical hypothyroidism in women with type 2 diabetes: the Fremantle diabestes study. Clin Endocrinol (Oxf) 2005;62(4):480-6.

[24] Ogbera AO, Kuku S, Dada O. The metabolic syndrome in thyroid disease: a report from Nigeria. Indian J Endocrinol Metab 2012;16(3):417-22.

[25] Pinchera A, Mariotti S, Barbesino G, et al. Thyroid autoimmunity and ageing. Horm Res 1995;43(1-3):64-8.

[26] Diez JJ. Hypothyroidism in patients older than 55 years: an analysis of the etiology and assessment of the effectiveness of therapy. J Gerontol A Biol Sci Med Sci 2002;57(5):M315-20.

[27] Arthur FKN, Adu-Frimpong M, Osei-Yeboah J, et al. The prevalence of metabolic syndrome and its predominant components among pre and post menopausal Ghanaian women. BMC Res Notes 2013;6:446.

[28] Agarwal G, Sudhakar MK, Singh M, Senthil N, et al. The prevalence of thyroid dysfunction among south Indian women with metabolic syndrome. JCDR 2011;5(2):152-4.

[29] Chugh K, Goyal S, Shankar V, et al. Thyroid function tests in metabolic syndrome. Indian J Endocrinol Metab 2012;16(6):958-61.
[30] Fletcher AK, Weetman AP. Hypertension and hypothyroidism. J Hum Hypertens 1998;12(2):79-82.

[31] Biondi B. Cardiovascular effects of mild hypothyroidism. Thyroid 2007;17(7):625-30.

[32] Rosenbaum M, Hirsch J, Murphy E, et al. Effects of changes in body weight on carbohydrate metabolism, catecholamine excretion, and thyroid function. Am J Clin Nutr 2000;71(6):1421-32.

[33] Zile MR, Brutsaert DL. New concepts in diastolic dysfunction and diastolic heart failure: Part II: causal mechanisms and treatment. Circulation 2002;105(12):1503-8.

[34] Mattace-Raso FUS, van der Cammen TJM, Hofman A, et al. Arterial stiffness and risk of coronary heart disease and stroke: the Rotterdam Study. Circulation 2006;113(5):657-63.

[35] Punia VPS. Study of metabolic syndrome and associated thyroid dysfunction in an urban population. JIACM 2010;11(3):184-6.

[36] Jayakumar RV. Hypothyroidism and metabolic syndrome. Thyroid Res Pract 2013;10(4):1-2.

[37] Lam KS, Chan MK, Yeung RT. High-density lipoprotein cholesterol, hepatic lipase and lipoprotein lipase activities in thyroid dysfunction--effects of treatment. Q J Med 1986;59(229):513-21.

[38] Dullaart RP, Hoogenberg K, Groener JE, et al. The activity of cholesteryl ester transfer protein is decreased in hypothyroidism: a possible contribution to alterations in high-density lipoproteins. Eur J Clin Invest 1990;20(6):581-7. 